\title{
EXPERIÊNCIAS DE INTERNACIONALIZAÇÃO DE PEQUENAS EMPRESAS DE SOFTWARE E CONHECIMENTOS OBTIDOS
}

\author{
Alessandra Herranz Gazquez, Hilka Pelizza Vier Machado, Arthur Gualberto Bacelar da Cruz Urpia ${ }^{1}$ \\ Centro Universitário de Maringá - UNICEUMAR, Paraná, (Brasil)
}

\section{DETALHES DO ARTIGO}

Recebido: 24 de maio de 2019

Aceito: 01 de dezembro de 2019

Disponível online: 01 de maio de 2020

Sistema de revisão "Double blind review"

Editor Científico

Ilan Avrichir

Palavras-chaves:

Processo de Internacionalização

Pequenas Empresas

Software

\begin{abstract}
RESUMO
Objetivo: o objetivo desta pesquisa foi identificar e analisar as formas de entrada e os conhecimentos obtidos por pequenas empresas de software em experiências de internacionalização.

Método: é um estudo qualitativo, realizado com cinco estudos de casos de pequenos empreendedores. Foram utilizados dados primários e secundários. Dados primários foram obtidos em nove entrevistas abertas e semiestruturadas, e os dados secundários em web sites das empresas. Os dados foram categorizados em formas de entrada e conhecimentos obtidos. Os dados desta última categoria foram complementarmente analisados com uso do software Iramuteq.

Principais resultados: como conhecimentos gerados, foram identificadas seis classes de conhecimentos, sendo: a) mercados e destinos; b) ação para colocar o produto no mercado internacional; c) apoio e busca de conhecimentos externos; d) necessidade de qualificação para o processo de internacionalização e parcerias locais; e) visão do mercado local; f) complexidade do processo de internacionalização.

Relevância/originalidade: o estudo das experiências de internacionalização e conhecimentos obtidos é uma abordagem original, pois destaca as formas de entrada e os conhecimentos obtidos por pequenas empresas de software em experiências de internacionalização.

Contribuições teóricas/metodológicas: os resultados mostraram que a aprendizagem nas experiências de internacionalização favoreceu o aumento do conhecimento de mercado internacional e contribuiu para melhoria de competitividade no mercado local.
\end{abstract}

\section{Introdução}

Empresas que atuam internacionalmente aprendem com o fluxo constante de novas demandas, oportunidades e desafios que a experiência internacional oferece (Cortezia \& Souza, 2007; Zarei, Nasseri, \& Tajeddin, 2011). Para pequenas empresas, Xie e Suh (2014) afirmam que a internacionalização é uma das principais decisões estratégicas para a sobrevivência em longo prazo. A internacionalização é importante porque ela propicia aprendizado às empresas e possibilita novos contatos que podem resultar em futuros negócios (Cortezia \& Souza, 2007). Ela se apresenta como um processo de aprendizagem e de conhecimentos de mercados (Armario, Ruiz, \& Armario, 2008). Quando empresas internacionalizam, adquirem conhecimento resultante das adaptações para atender às demandas de clientes (Ramos \& Alperstedt, 2010; Rezende \& Campos, 2010; Silva, Chauvel, \& Bertrandt, 2010).

Entre as indústrias que internacionalizam, a de software se caracteriza por ser de forte crescimento global e de mudanças tecnológicas frequentes (Rivero, 2010). Embora nos últimos anos a produção de software no Brasil tenha tido destaque, a atuação do setor no exterior não é tão expressiva (Souza, Vasconcelos, \& Corrêa, 2012). Políticas nacionais têm incentivado a internacionalização de empresas (Agência Brasileira de Promoção de Exportações e Investimentos [ApexBrasil], 2014), porém cabe salientar o número reduzido de empresas de base tecnológica que operam em mercados internacionais (Ribeiro, Oliveira Junior, \& Borini, 2012). Dib, Rocha e Silva (2010) comentam as dificuldades que empresas brasileiras de software enfrentam para se 
internacionalizarem, quando comparadas a empresas europeias. Para esses autores, as empresas brasileiras têm mais dificuldade de se internacionalizar, pois o Brasil é um país que tradicionalmente exporta commodities e não tem o mesmo número de empresas born globals como a Europa. Além disso, em geral, empresas brasileiras não percebem a internacionalização como um processo racional, com oportunidades de mercado (Silva et al., 2010). Essa situação mostra a necessidade de estudos sobre a internacionalização dessas empresas, buscando resposta à questão: Quais os conhecimentos oriundos da experiência de internacionalização por pequenas empresas de software?

Embora estudos anteriores tenham focado o processo de internacionalização de empresas de software (Burzynski, Graeml, \& Balbinot, 2010; Dib et al., 2010; Ibeh, Kasem, 2011; Ribeiro et al. 2012; Souza et al., 2012), eles não foram suficientes para evidenciar os efeitos dessas experiências sobre a geração de conhecimentos para as empresas. Focar a geração de conhecimento é importante para empresas de software, pois elas necessitam incorporar conhecimento em práticas e estratégias (Tzortzaki \& Mihiotis, 2014; Makambe, 2015). Diante disto, realizou-se esta pesquisa junto a pequenas empresas de software que se internacionalizaram, com o objetivo de identificar e analisar as formas de entrada e os conhecimentos obtidos por elas nas experiências de internacionalização. Para alcançar o referido objetivo foi desenvolvido um estudo qualitativo junto a cinco casos de empresas de software, sendo duas com sede na Comunidade Valenciana e três no Estado do Paraná. Os dados foram analisados com apoio do software Iramuteq.

Como contribuições, a pesquisa, ao analisar a internacionalização de empresas de software, identificou as categorias: planejamento, adaptação e ações para a internacionalização, detalhando cada categoria em diversas classes. Como contribuição prática, os resultados apresentam elementos para outras empresas de software que pretendem se internacionalizar, bem como para a formulação de políticas voltadas a internacionalização dessas empresas. Na seção seguinte apresenta-se a revisão da literatura, focando resultados de estudos anteriores sobre conhecimento e empresas de software. Em seguida, foram descritos os procedimentos metodológicos utilizados para o desenvolvimento da pesquisa e os resultados obtidos, com a respectiva análise.

\section{Conhecimento para empresas de software}

O conhecimento deriva de dados e informações, ele representa a informação combinada com a experiência, contexto, interpretação e reflexão (Basañez, 2014; Davenport \& Prusak, 2001). Nas organizações, o conhecimento, está presente em rotinas, processos, práticas e normas institucionais (Cantú, 2004). Ele é dependente do contexto e orienta a ação dos indivíduos (Amaral, Ribeiro, \& Sousa, 2007).

Para organizações, o conhecimento possibilita a geração de ações direcionadas para satisfazer as demandas do mercado, sendo um ativo importante para os resultados organizacionais (Basañez, 2014). Uma empresa é geradora de conhecimento desde que tenha os recursos para aprender, ou seja, desde que consiga extrair e converter os saberes explícitos e tácitos em ciclos de externalização, combinação, internalização e socialização, utilizando as aprendizagens adquiridas para formular novas aprendizagens (An, Deng, Chao, \& Bai, 2014; Nonaka \& Takeuchi, 1997).

Os conhecimentos servem para mudar produtos e processos, além de sustentar o caráter distintivo das empresas e sua competitividade (An et al., 2014). A articulação de recursos baseados em conhecimento poderá contribuir para maior desempenho (Sullivan \& Marvel, 2011). No caso de empresas de software, estas são intensivas em trabalho intelectual e o conhecimento é um ativo estratégico, direcionado para o fortalecimento das capacidades organizacionais e para melhoria da competitividade. No entanto, um dos desafios para essas empresas é administrar o conhecimento, um processo dinâmico e complexo que se desenvolve por meio da aquisição (fontes externas ou internas), assimilação, adaptação e geração de novos conhecimentos (Rivero, 2010). Empresas de software podem adotar diferentes estratégias para gerar e compartilhar o conhecimento, tais como: a) repositórios e livrarias do conhecimento, que servem para documentar o conhecimento tácito, registrar o conhecimento existente; b) ferramentas da comunidade de trabalhadores: mecanismos que distribuem as tarefas, documentam projetos; c) cartografia do conhecimento, uma ferramenta para mapear e categorizar o conhecimento, reconhecendo as 
informações disponíveis nas empresas e; d) fluxo do conhecimento, uma ferramenta que permite a interação das anteriores entre os diferentes tipos de conhecimento (Rivero, 2010).

Rivero (2010) salienta que a administração do conhecimento em empresas de software impulsiona a aprendizagem organizacional e torna possível a difusão de melhores práticas dentro da organização, assim como a definição e o estabelecimento de processos para as áreas. Por meio da administração do conhecimento, são estabelecidas redes de trabalho internas entre as áreas da empresa e uma plataforma comum de interação entre as pessoas da empresa para que possam intercambiar informações e gerar conhecimento na empresa.

\section{Considerações teóricas sobre Internacionalização}

O processo de internacionalização pode ser entendido como um processo gradual de envolvimento em operações internacionais (Cunha, 2010; Johanson \& Vahlne, 1977). Para Lemes e Prates (2014, p. 165), “a internacionalização é um processo genuíno de aprendizagem e de desenvolvimento do conhecimento da empresa nos mercados estrangeiros" e ela resulta de conhecimento acumulado (Mejri \& Umemoto, 2010).

A internacionalização propicia às empresas vantagens, como a geração de retornos no mercado local, na medida em que, ao ampliar o mercado, a empresa adquire novos conhecimentos e tecnologias (Stal, 2010). Sullivan e Marvel (2011) consideram que a obtenção de conhecimentos de mercado representa uma oportunidade para atrair clientes e ampliar o mercado de atuação. Além disso, no caso de grandes empresas, a internacionalização pode contribuir para a transferência de conhecimentos para subsidiárias, aumentando assim as capacidades dinâmicas destas (França, Maccarri, Da Costa, 2019).

Diferentes abordagens explicam a internacionalização de empresas: teoria econômica e teoria comportamental, além de modelos relacionados à inovação, à pré-exportação, abordagem das redes e empreendedorismo internacional (Mejri \& Umemoto, 2010). A abordagem econômica é precursora nos estudos sobre comércio internacional. Para ela, a internacionalização é compreendida por meio do ciclo de vida do produto e de custos de transações (Mejri \& Umemoto, 2010). As empresas precisam estar preparadas para competir com as empresas já estabelecidas em mercados estrangeiros, a fim de obter vantagens para compensar os custos de operar em ambientes novos e distantes de suas origens. Esta abordagem é orientada às decisões que maximizem lucros (Linzemeyer, Souza, \& João, 2012). Segundo a abordagem econômica, para se internacionalizar as empresas necessitam possuir certos tipos de vantagens sobre seus competidores que justifiquem o investimento direto no exterior. Essas vantagens incluem as relacionadas aos ativos tangíveis e intangíveis, como marcas, capacitação tecnológica, qualificação da mão de obra, que permitem que as firmas aproveitem as vantagens de localização oferecidas pelos países (Souza et al., 2012).

A abordagem comportamental considera que a internacionalização pode ser interpretada como um processo de aprendizagem gradual, na medida em que a organização adquire informações sobre o mercado externo. Para a escola de Upsala, o processo de internacionalização ocorre como uma sequência de estágios nos quais a empresa adquire conhecimento do mercado externo ao longo do tempo, envolvendo-se gradualmente e expandindo seus negócios para um país estrangeiro de cada vez (Johanson \& Vahlne, 1977). O aprendizado decorre do acúmulo de conhecimentos adquiridos por meio do processo experiencial, que se processa em três etapas: a) a empresa realiza exportação por meio de um agente no país de destino; b) após adquirir determinado nível de conhecimento, a empresa aprofunda suas relações, abrindo uma subsidiária de vendas; c) a empresa implanta uma unidade de produção no novo país (Johanson \& Vahlne, 1977). Desta forma, empresas tendem a entrar primeiro em mercados menos distantes psiquicamente, isto é, em mercados que apresentem cultura e ambientes similares, a fim de diminuir os riscos provenientes das incertezas (Johanson \& Vahlne, 2009; Linzemeyer et al., 2012; Ramos \& Alperstedt, 2010). A empresa se internacionaliza investindo recursos de maneira gradual, isso permite a entrada no mercado estrangeiro, partindo de um envolvimento pequeno e controlado para um maior envolvimento, de acordo com o grau de confiança e segurança (Lemes \& Prates, 2014). Este modelo foi objeto de críticas por não considerar aspectos como as redes de cooperação, a inovação de produtos e processos e a internacionalização acelerada (Mais, Carvalho, Amal, \& Hoffmann, 2010). 
Xie e Suh (2014) apresentam outro modelo de internacionalização, relacionado com a inovação, que sugere que os gestores precisam acumular informações a fim de reduzir riscos e de aumentar o aprendizado. Outra abordagem é a do empreendedorismo internacional, definido como a criação, descoberta, exploração e avaliação de oportunidades fora do mercado nacional, com o objetivo de desenvolver bens e serviços (Mcdougall \& Oviatt, 2003). Cabe ao empreendedor identificar as oportunidades do mercado internacional e desenvolver as habilidades e estratégias, visando explorar as oportunidades de internacionalização (Anderson, 2000). O empreendedorismo internacional expõe a empresa à necessidade de desenvolvimento de novas e diferentes habilidades (Zahra, Ireland, \& Hitt, 2000). Por outro lado, ele representa um risco para a empresa, à medida que, no momento em que uma empresa opta por sair do mercado doméstico, ela precisa se adequar às questões culturais, legais, tributárias, às redes, tecnologias e outros elementos (Mejri \& Umemoto, 2010; Rezende \& Campos, 2010), a fim de enfrentar incertezas e falta de conhecimento geral de como prosseguir uma operação de negócios em um ambiente não familiar (Cunha, 2010; Souza et al., 2012).

A fim de minimizar os riscos do processo de internacionalização, as empresas buscam conhecimentos. O conhecimento do mercado diz respeito à identificação de oportunidades e ameaças oriundas da decisão de internacionalização, sendo que ele deriva de maior conhecimento de necessidades de clientes e, assim, favorece o aprendizado sobre possibilidades de ofertar novos produtos (Silva et al., 2010). Além do conhecimento de mercado, as empresas precisam obter informações sobre o ambiente - político, econômico, cultural e social do país de destino (Cortezia \& Souza, 2007; Ramos \& Alperstedt, 2010). Javernick-Will (2009) descreve três elementos associados à internacionalização que a empresa precisará conhecer para se lançar no mercado externo: a) elementos regulativos, os quais incluem leis $e$ regulamentos, leis operacionais, conhecimento de governo e processo de aprovação dos projetos; b) elementos normativos: incluem regras, sanções e incentivos, em projetos internacionais. O conhecimento normativo inclui as práticas de trabalho, normas sociais, expectativas e preferências locais, normas de produtividade e conhecimento de mercado; c) elementos cognitivo-cultural: estes elementos incluem as crenças que são socialmente construídas e que fornecem modelos para enquadrar as percepções e decisões individuais.

Convém salientar que a internacionalização não é necessariamente dependente de trajetórias internacionais (Limp, Rezende, \& Versiani, 2018), contudo, uma vez internacionalizadas, um dos resultados alcançados pelas empresas é a aprendizagem decorrente da atuação internacional (Cortezia \& Souza, 2011).

À medida que a empresa expande para novos mercados, é capaz de utilizar os conhecimentos e as habilidades desenvolvidas nos mercados de origem e incorporar as novas experiências obtidas em mercados internacionais, incrementando, desta forma, seu conhecimento inicial. Empresas que se internacionalizam podem melhorar $\mathrm{O}$ seu desempenho (Javernik-Will, 2009), por meio de ganhos em termos de economias de escala, como também podem apresentar menor dependência e valorização no mercado local. Nesse sentido, a internacionalização pode contribuir para melhoria dos produtos e serviços ofertados pela empresa (Stal, 2010) e pode representar um recurso de aprendizagem para empresas de software.

\subsection{Internacionalização de Empresas de software}

A indústria de software inclui um grupo de empresas que têm habilidades para oferecer serviços associados ao desenvolvimento de softwares, sendo um setor com elevada diversidade interna (Burzynski, Graeml, \& Balbinot, 2010). Essas empresas estão constantemente confrontadas por novos produtos e tecnologias que emergem em mercados globais (Vasilchenko \& Morrish, 2011). A internacionalização é importante para elas se inserirem em mercados globais e não ficarem apenas dependentes do mercado doméstico (Souza, Vasconcelos, \& Corrêa, 2012).

No Brasil, foi a partir dos anos 1990 que essas empresas se orientaram para o mercado. No entanto, o país não se destaca internacionalmente como um produtor de softwares. Mesmo assim, algumas empresas tem se internacionalizado, na medida em que elas vislumbram uma oportunidade de atuarem no mercado internacional e de se fortalecerem para fazer face aos concorrentes (Souza, Vasconcellos, \& Corrêa, 2012). 
Entre as empresas de software que se internacionalizaram, pesquisas destacam a influência dos relacionamentos e das redes, tanto redes sociais, como redes de negócios (Ibeh \& Kasem, 2011; Vasilchenko \& Morrish, 2011). Para Ibeh e Kasem (2011), é principalmente nos momentos iniciais que as redes são importantes para auxiliar na seleção dos mercados e na velocidade do processo de internacionalização. As redes de negócios podem ainda contribuir para superar limitações de recursos e para adquirir conhecimento sobre o mercado local e sobre clientes (Vasilchenko \& Morrish, 2011). No entanto, o comprometimento e a experiência dos empreendedores também podem facilitar a internacionalização (Dib, Rocha, \& Silva, 2010; Ibeh \& Kasem, 2011), bem como a qualidade dos produtos (Ibeh \& Kasem, 2011).

Empresas de software, para se internacionalizar, enfrentam algumas dificuldades. Uma delas é o idioma inglês (Burzynski, Graeml, \& Balbinot, 2010). Outra é a influência de aspectos socioculturais, como mostra o estudo de Massago et al. (2018) sobre o desenvolvimento distribuído de softwares.

Eles realizaram uma revisão sistemática da literatura em publicações do ano de 2001 até 2014 e identificaram 14 aspectos comuns representativos de aspectos socioculturais em $70 \%$ das publicações, sendo eles: idioma, distância de poder, individualismo versos coletivismo, orientação de longo versus curto prazo, aversão à incerteza, masculinidade versus feminidade, estilo de comunicação, legislação versus burocracia, religião, diferentes práticas de trabalho, moral/ética, confiança e valores. Em outro estudo, Massago et al. (2019) constataram que 97,29\% das áreas chave no desenvolvimento do software sofreram influência dos aspectos socioculturais.

Embora as empresas enfrentem esses desafios para se internacionalizarem, elas podem obter vantagens, tais como: aumentar a funcionalização do produto; maximizar investimentos na qualificação de pessoas, em pesquisa e desenvolvimento, além de propiciar economia para os clientes, contribuindo para que eles possam ganhar em escala e produtividade (Souza, Vasconcellos, \& Corrêa, 2012). Parte-se também da premissa que empresas de software que se internacionalizam acumulam aprendizado decorrente das experiências alémfronteiras, o que foi objeto desta pesquisa.

\section{Procedimentos Metodológicos}

Este é um estudo qualitativo, realizado com o método de estudo de casos múltiplos (Yin, 2015). As unidades de análise foram empresas que se internacionalizaram e que atuam na área de software. Foram selecionadas cinco empresas de pequeno porte, sendo três no Brasil e duas na Espanha. A escolha de empresas em dois países teve como objetivo obter maior amplitude de resultados, na medida em que foram buscados contextos distintos de atuação e de destino das empresas. No caso brasileiro, as empresas estão inseridas em um arranjo produtivo local e todas tiveram experiências de internacionalização e, no caso espanhol, as empresas estão inseridas em parque tecnológico e se internacionalizaram.

Os dados foram coletados por meio de dados primários e secundários. Dados primários foram obtidos em entrevistas semiestruturadas, a partir de três questões principais: a) fale sobre sua experiência de internacionalização; b) fale sobre os meios que utilizou para decidir se internacionalizar e; c) comente os conhecimentos decorrentes dessa experiência. Os participantes foram selecionados, no caso brasileiro, as três empresas de software eram vinculadas a um arranjo produtivo local de um Estado localizado no sul do Brasil e que se internacionalizaram; no caso espanhol, as duas empresas foram indicadas em um parque tecnológico que concentra empresas de software.

Os participantes foram contatados e mediante concordância na participação, eles assinaram o Termo de Livre consentimento e esclarecimento da pesquisa. Foi assegurada a confidencialidade dos dados e os participantes estão nominados por meio de códigos. No total, foram realizadas nove entrevistas, totalizando 10 horas e trinta minutos de gravações. Para o caso 1 foram realizadas entrevistas com o empreendedor e com o diretor de inovação, apresentadas como A1E1 e A1E2, respectivamente. Para o caso 2 foi realizada uma entrevista com o empreendedor (A2E1). Para o caso 3 foram realizadas duas entrevistas, com cada um dos sócios, representadas no texto como A3E1 e A3E2. Para O caso 4, foram realizadas duas entrevistas, com o empreendedor e com o diretor de inovação (A4E1, A4E2) e, por fim, no caso 5 foram realizadas duas entrevistas, com o diretor e com o empreendedor (A5E1, A5E2). As entrevistas foram gravadas 
mediante autorização dos respondentes, e, em seguida, transcritas. Além de entrevistas, dados secundários foram obtidos em website das empresas. Segundo Yin (2015), o uso de múltiplas fontes de evidência na pesquisa de estudo de caso permite que o pesquisador aborde uma variação maior de aspectos históricos e comportamentais, a triangulação dos dados reforça a validade do constructo do estudo de caso.

A análise de dados foi realizada em duas etapas. Primeiramente foi utilizada a análise de conteúdo, um conjunto de técnicas de análise que usa procedimentos sistemáticos e objetivos de descrição do conteúdo das mensagens (Bardin, 2010). As entrevistas foram inicialmente analisadas na íntegra e depois passaram por um processo de categorização. As categorias foram definidas com apoio do software NVivo, versão 11, e a categorização resultou em dois temas, sendo: formas de entrada e conhecimentos obtidos na internacionalização.

Para a categoria conhecimentos obtidos na internacionalização, os dados foram, em seguida, analisados utilizando o software Iramuteq (Interface de $R$ pour les Analyses Multidimensionnelles de Textes et de Questionnaires). Este software, que foi desenvolvido por Pierre Ratinaud, possibilita diversos tipos de análise de dados textuais, desde a análise lexicografia básica, como o cálculo de frequência de palavras, até análises multivariadas, tais como a classificação hierárquica descendente (CHD) e a análise de similitude (Ramos, Lima, \& Rosa, 2018). O CHD, que é obtido a partir do Método de Reinert, realiza a subdivisão do corpus textual em função dos seus respectivos vocábulos, em que, utilizando-se de cálculos estatísticos, proporciona o surgimento de classes com vocábulos semelhantes entre si e diferente das demais classes (Ramos, Lima, \& Rosa, 2018). Também a partir do Método de Reinert, é realizado o teste do qui-quadro $\left(x^{2}\right)$. Este teste permite avaliar, do ponto de vista quantitativo, a associação entre os vocábulos e as classes. Para que a associação seja estatisticamente significativa, os valores dos qui-quadrado terão que ser superiores a $3,8(p<0,05)$ (Salviati, 2017).

O CHD ainda possibilita a criação de um Dendograma que, segundo Camargo e Justo (2013, p. 5), "apresenta as partições que foram feitas no corpus até que se chegasse às classes finais", além de ilustrar a interação entre as classes. A partir do CHD, o corpus textual criado com os dados desta pesquisa foi agrupado em sete classes de palavras: classe 1 (visão do mercado local), classe 2 (complexidade do processo de internacionalização), classe 3 (apoio e busca de conhecimentos externos), classe 4 (necessidade de pessoas qualificadas para o processo de internacionalização e parcerias locais), classe 5 (ação para colocação do produto no mercado internacional), classe 6 (mercados e destinos) e classe 7 (adaptação a normas e mercados). Após a categorização, também com o uso do Iramuteq, foi realizada a análise fatorial por correspondência (AFC), que permite que sejam verificadas as relações entre as classes em um plano cartesiano, demonstrando a localização dessas classes e sua interação (Nascimento \& Menandro, 2006), bem como a nuvem de palavras, que é um tipo de análise lexical mais simples, mas que contribui para a análise textual ao possibilitar a rápida identificação das palavras chave de um corpus de texto (Camargo \& Justo, 2013).

\section{Resultados e Análises}

\subsection{Breve perfil das empresas}

A empresa A é sediada na Comunidade Valenciana e atua com software de gestão na área hospitalar. Foi criada há 6 anos. Atuante na Europa e América Latina, a primeira filial foi criada no Chile, país onde realizou a sua primeira experiência de internacionalização. Atualmente atua nos Estados Unidos e Arábia Saudita, por meio de representantes.

A empresa B foi fundada em 1993, no estado do Paraná. Iniciou seus contatos com o Japão em 1999 e em 2000 fez o primeiro contrato de comercialização. Adaptou para o idioma japonês o software de gestão para lojas de pequeno porte e comercializava o software no idioma português para decasséguis que trabalhavam no Japão. A internacionalização ocorreu de forma inesperada, por meio de contato com um órgão do Estado, que estimulou e forneceu suporte em todo o processo do relacionamento Brasil/Japão.

A empresa C é uma sociedade limitada de capital privado com sede no estado do Paraná, especializada no desenvolvimento de soluções de software, tem 22 anos e atende 20 das maiores empresas do país. Internacionalizou, inicialmente para a Índia. Em 2008, fez a primeira exportação. A motivação da primeira internacionalização foi a busca por mão de obra.

A empresa $D$ tem sede em Valencia e desenvolve sistemas de gestão da informação para a área de 
saúde. Atua em várias cidades da Espanha e na América Latina (Argentina, Chile e México). A primeira internacionalização ocorreu em 2001.

A empresa E é uma born global projetada no Brasil há três anos para atuar nos Estados Unidos. Atualmente está presente em 140 países e atua no desenvolvimento de sistemas de gerenciamentos de processos estratégicos para pequenas e médias empresas.

\subsection{Formas de entrada na internacionalização}

As empresas se internacionalizaram utilizando formas diferenciadas de inserção no mercado local. Uma das maneiras foi a identificação de algum contato local, como ocorreu com a empresa A1 e contato com outras empresas que se internacionalizaram, que foi o caso das duas empresas espanholas. Duas empresas brasileiras entraram no mercado externo com apoio de órgão público (A2 e A3). A empresa $A 1$, além do contato local, utilizou também um consultor para obter mais informações do mercado alvo.

Outra estratégia, adotada pelas empresas A2 e A3, foi viajar para o país para o qual queriam internacionalizar seus produtos, a fim de conhecer e entender as necessidades e possíveis áreas de negócio, como narrado pelos entrevistados:

(...) o nosso caso era entender como era fazer negócio no exterior, começamos a participar de alguns eventos. Me associei a uma organização internacional que atuava junto à Confederação das indústrias do Paraná e existiam algumas missões para a Europa e aí participei de algumas visitas, eles te dão todas as informações que você precisar (A2E2).

Então a viagem que fiz para a Índia não foi só para ir às empresas, eu fazia também alguma coisa fora e fazia contato com outros empresários, com outras empresas, eu tentava ver quais outras oportunidades a gente tinha, (...) (A3E1).

Quanto ao contato com outras empresas, esta foi uma estratégia utilizada pelas empresas espanholas, sendo que a empresa A4 fez também uma parceria com outra empresa para explorar novos mercados internacionais, o que pode ser evidenciado nos seguintes excertos das entrevistas:
Utilizamos nossos próprios contatos e fomos fazendo. Ou seja, uma rede de contato com outras empresas parecidas com a nossa que já abriram mercado e já venderam seus produtos em outros países (...) ou seja, digamos que é uma relação onde tentamos transmitir informações que nos beneficia a todos, um transmite para o outro (...) tem um regional que é o IVACE, por exemplo, que é uma entidade que tem escritórios em diferentes países e tem gente para assessorar para entrar nesses mercados e depois tem o ICE Instituto de Comercio Exterior, mas nós realmente não utilizamos (A4E1).

Então estivemos com eles e eles visitaram nosso escritório faz três anos também, então em 2015 fizemos os primeiros cinco hospitais com eles, então como eles também têm a representação na Bolívia, Paraguai, Uruguai e toda a América do Sul, queremos atuar com eles e depois, se funcionar bem, ampliar para mais países (A4E1).

Por fim, como uma born global, a empresa A5 nasceu internacionalizada em 2014 no Vale do Silício, pois visava acesso a capital de investidores, como mostra o excerto da entrevista:

A gente foi para uma start-up para o Vale do Silício e lá a gente teve acesso a capital, mentoria, etc. (...) fui conversando, perguntando com quem já tinha feito em outros países, batendo papo, um processo que não teve nada de especial, foi só sentar e ir atrás, tinha contato com aceleradora, eles já estavam informados quanto a tributos, receita fiscal, como funciona (A5E1).

\subsection{Conhecimentos obtidos na internacionalização}

O conteúdo das entrevistas que versava sobre os conhecimentos oriundos da internacionalização foi transformado em um corpus textual e foi composto por cinco textos, separados em 105 segmentos de textos (ST), dos quais 91 foram classificados pelo IRaMuTeQ, resultando em um aproveitamento de 86,67\%. Emergiram 3.709 ocorrências (palavras, formas ou vocábulos), com 708 lemas, 561 formas ativas, 141 formas suplementares e 604 palavras com uma única ocorrência (intitulado de hapax). O conteúdo analisado foi categorizado em sete classes: classe 1, com 10 ST (11\%); classe 2, com 10 ST (11\%); classe 3, com 15 ST (16,5\%); classe 4, com 13 ST (14,3\%); classe 5, com 16 ST (17,6\%); classe 6, com 17 ST $(18,7 \%)$, e; classe 7 , com 10 ST (11\%), conforme Figura 1. 


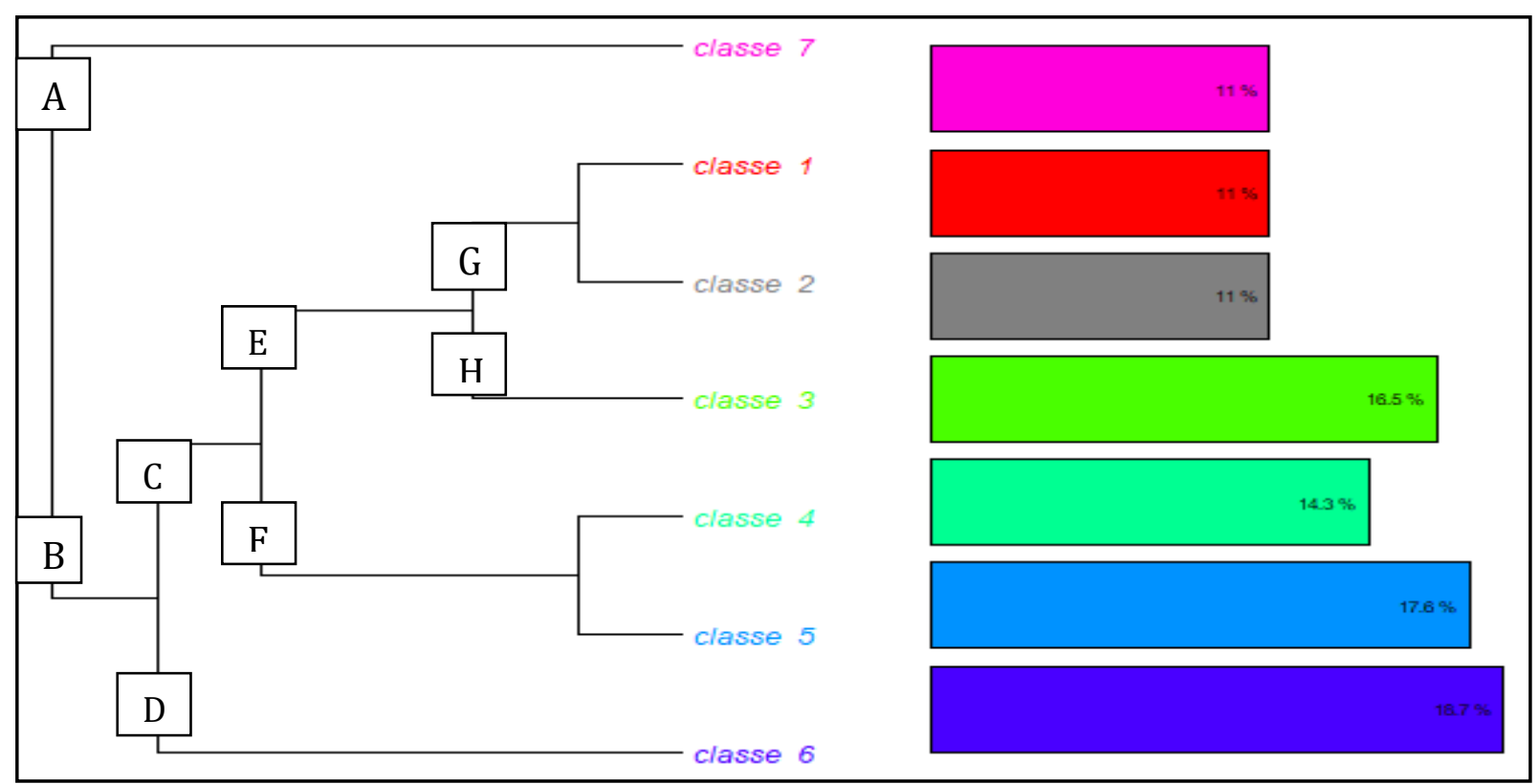

Figura 1. Dendograma das classes

Fonte: Elaboração própria com dados da pesquisa, 2019 e gerados pelo aplicativo IRaMuTeQ.

Na Figura 1, observa-se que as 7 classes geradas se encontram, inicialmente, em 2 subcorpus. O Subcorpus A é composto pela classe 7 . O subcorpus B possui 2 ramificações ( $C$ e $D$ ). A ramificação $D$ é composta pela classe 6 . Já a ramificação $C$ possui outras duas subdivisões (E e F), com a subdivisão $F$ sendo composta pelas classe 4 e 5 e a subdivisão $E$ sendo composta pelos subgrupos $G$, que inclui as classe 1 e 2 , e $\mathrm{H}$, que abrange a classe 3 . A Figura 2 apresenta as palavras pertencentes a cada classe e as relações entre as classes.

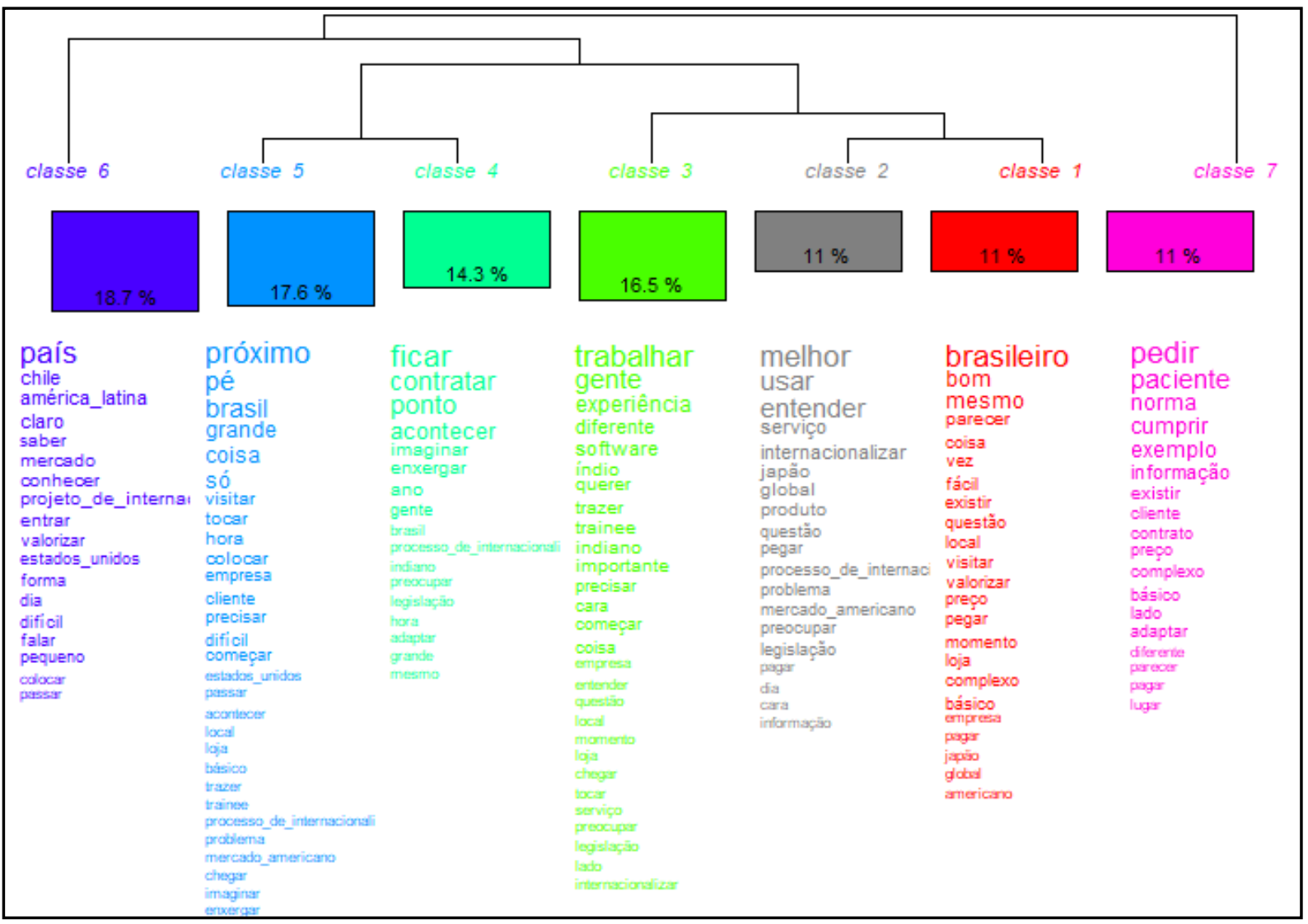

Figura 2. Filograma sobre as representações das Classes

Fonte: Elaboração própria com dados da pesquisa, 2018, e gerados pelo software IRaMuTeQ 
A classe 7, sub categorizada como 'adaptação a normas e mercados', compreende $11 \%$ do total do corpus analisado e é composta por palavras e radicais com intervalo qui-quadrado entre $X^{2}=7,87$ (cada) e $X^{2}=52,49$ (pedir). As seguintes palavras se destacam: pedir $\left(X^{2}=52,49\right)$, paciente $\left(X^{2}=33,89\right)$, norma $\left(X^{2}=\right.$ $25,13)$, cumprir $\left(X^{2}=25,13\right)$, exemplo $\left(X^{2}=23,37\right)$, informação $\left(X^{2}=17,53\right)$, existir $\left(X^{2}=9,83\right)$, cliente $\left(X^{2}\right.$ $=6,51)$ e contrato $\left(X^{2}=4,55\right)$. Esta classe demonstra a preocupação das empresas em se adaptar às normas e mercados externos, de tal forma a viabilizar o processo de internacionalização, tal como pode ser observado no seguinte fragmento de entrevista:

No assunto que nós trabalhamos é que existe em cada país normas e leis diferentes, sobretudo no setor de saúde, por exemplo, o manejo de medicamentos. (...) Por exemplo, no México existiam normas muito precisas e muito documentadas de que informações eram requeridas para hemodiálise, ou seja, haviam inclusos formulários de como teria que fazer para o governo..., em alguns países pedem o formulário dos dados do paciente, em alguns lugares pedem a religião do paciente e em outros não pedem, são exemplos que parece pouco menores, mas que te obrigam a pedir mais informações (A4E1).

A classe 6, denominada 'mercado e destinos', compreende $19 \%$ do total do corpus analisado e é composta por palavras e radicais com intervalo quiquadrado entre $X^{2}=4,7$ (antes) e $X^{2}=48,94$ (país). As seguintes palavras se destacam: país $\left(X^{2}=48,94\right)$, Chile $\left(X^{2}=18,21\right)$, América Latina $\left(X^{2}=18,21\right)$, mercado $\left(X^{2}=8,92\right)$, projeto de internacionalização $\left(X^{2}=8,74\right)$, entrar $\left(X^{2}=8,74\right)$, conhecer $\left(X^{2}=8,74\right)$, valorizar $\left(X^{2}=4,7\right)$ e Estados Unidos $\left(X^{2}=4,15\right)$. Esta classe retrata os mercados e destinos das empresas entrevistas, tal como comentado pelos entrevistados:

Temos um produto e a marca, mas tem que colocar uma área no país para que realmente tenhas resultados, é o que fizemos no Chile e na realidade tivemos resultados (A1E1).

Hoje me dou conta que fizemos muito bem, o mercado europeu é mais difícil de entrar e sabe que somos o irmão pobre, por isso nosso projeto de internacionalização é ir para a América Latina, bom e estamos lá, agora é expandir para outros países, fortalecer nosso produto e seria melhor ir para os Estados Unidos porque então teríamos poder de negociação com o mercado europeu, pois são mais potentes e mais difíceis de entrar...., para o momento nos centramos na América Latina que tem muito mercado para descobrir, e cremos que nos será muito vantajoso porque há muitos países, alguns pequenos, mas outros com muito potencial... Mas antes de chegar ao Brasil podemos avançar com o nosso projeto de internacionalização indo a todos aqueles países que falam o idioma espanhol, que são muitos: Argentina, Peru, Colômbia e Chile (A4E1).

Do que eu percebi, agora tem que ver pelo lado do consumidor do mercado americano, pois eles têm restrições com outros países, mas se colocar outra pessoa dos Estados Unidos falando com ele já quebra essa barreira (A3E1).

A classe 3, denominada de 'apoio e busca de conhecimentos externos', compreende $16,5 \%$ do total do corpus analisado e é composta por palavras e radicais com intervalo qui-quadrado entre $X^{2}=5,68$ (parte) e $X^{2}=32,92$ (trabalhar). As seguintes palavras se destacam: trabalhar $\left(X^{2}=32,92\right)$, gente $\left(X^{2}=\right.$ $22,79)$, experiência $\left(X^{2}=15,72\right)$, diferente $\left(X^{2}=9,17\right)$, software $\left(X^{2}=9,11\right)$, trazer $\left(X^{2}=5,68\right)$, trainee $\left(X^{2}=\right.$ $5,68)$, indiano $\left(X^{2}=5,68\right)$ e importante $\left(X^{2}=5,68\right)$. Esta classe demonstra o esforço das empresas em buscar apoio e conhecimentos externos para compreender a dinâmica do novo mercado, como comentaram os entrevistados:

Quando a gente foi para a Índia a gente tinha trazido um indiano para cá, um trainee que trabalhou com a gente aqui em torno de um ano e meio, ele foi o primeiro, nosso elo de confiança lá e quem ajudava a gente. (...), ele trazia para a gente muito conteúdo em relação ao que era válido e o que não era, (A3E1).

Trabalhamos com parceiros locais, pois para nós é muito importante trabalhar com gente que conhece o local (A1E2).

A classe 1, denominada 'visão do mercado local', compreende $11 \%$ do total do corpus analisado e é composta por palavras e radicais com intervalo quiquadrado entre $X^{2}=4,51$ (você) e $X^{2}=45,55$ (brasileiro). As seguintes palavras se destacam: brasileiro $\left(X^{2}=45,55\right)$, bom $\left(X^{2}=20,36\right)$, mesmo $\left(X^{2}=\right.$ $20,28)$, parecer $\left(X^{2}=6,51\right)$, fácil $\left(X^{2}=4,55\right)$ e você $\left(X^{2}\right.$ $=4,51)$. Esta classe apresenta a nova visão do mercado local após a internacionalização, tal domo os excertos ilustram: 
Foi bacana porque quanto mais força a gente fazia para ir para fora e concretizar o nosso processo de internacionalização, mais a gente aumentava a nossa musculatura aqui no Brasil e mais competitivo a gente ficava no Brasil mesmo. Então, isso favoreceu a gente ter mais contratos no Brasil (A3E2).

O que eu aprendi é assim, produto é o sine qua non, é o básico, se você tem um produto bom, você tem viabilidade de ter competitividade global. A principal coisa é as empresas brasileiras não valorizam isso. É subvalorizada a qualidade do produto e subvalorizada a questão do design. Até mesmo meus amigos de outras empresas de tecnologia brasileiras têm uma preocupação tão grande com design, fica mexendo no design o tempo todo, porque o produto tem que ser competitivo, pois é o que o mercado demanda. (A5E1).

A classe 2, denominada 'complexidade do processo de internacionalização', compreende 11\% do total do corpus analisado e é composta por palavras e radicais com intervalo qui-quadrado entre $X^{2}=6,07$ (produto) e $X^{2}=25,76$ (melhor). As seguintes palavras se destacam: melhor $\left(X^{2}=25,76\right)$, usar $\left(X^{2}=\right.$ $20,36)$, entender $\left(X^{2}=16,51\right)$, serviço $\left(X^{2}=9,83\right)$, internacionalizar $\left(X^{2}=9,83\right)$, Japão $\left(X^{2}=6,51\right)$, global $\left(X^{2}=6,51\right)$ e produto $\left(X^{2}=6,07\right)$. Esta classe denota a complexidade do processo de internacionalização que requer diferente tipos de novos conhecimentos, tais como o conhecimento do mercado e de aspectos legais, como pode ser melhor evidenciado nos seguintes trechos:

A gente passou a ter de entender a legislação por exemplo, de exportação de software e até entender o legislador, porque ele não sabe o que precisa fazer ou o que está fazendo porque nessa questão de internacionalização eu, por exemplo, pagava impostos que não deveria pagar porque o serviço estava sendo prestado fora, então, acho que o primeiro problema para se internacionalizar foi entender melhor a legislação (A2E1).

Tem que primeiro entender o grupo alvo, verificar qual vai ser a aderência do produto e aí sim se preocupar com a parte jurídica. (A3E1).

Essa aprendizagem, na verdade, é enxergar o mercado, o que está acontecendo, exceto produtos de manufatura, a logística é meio global, o cara não tem muita deficiência por questão de logística e você é obrigado a agir localmente (A5E2).
A classe 4, denominada 'necessidade qualificação para o processo de internacionalização e parcerias locais', compreende $14,3 \%$ do total do corpus analisado e é composta por palavras e radicais com intervalo qui-quadrado entre $X^{2}=6,95$ (verdade) e $X^{2}$ $=26,4$ (ficar). As seguintes palavras se destacam: ficar $\left(X^{2}=26,4\right)$, ponto $\left(X^{2}=18,66\right)$, contratar $\left(X^{2}=18,66\right)$, acontecer $\left(X^{2}=14,39\right)$, imaginar $\left(X^{2}=6,95\right)$ e enxergar $\left(X^{2}=6,95\right)$. Os seguintes trechos ilustram esses sentidos:

O próprio Brasil é um mercado muito grande, referência em alguns hospitais, mas temos que adaptarmos a língua, teria que contratar gente que fala o idioma português (A4E1).

Eu fiquei 45 dias no escritório em Tóquio, eles têm esse trabalho para as empresas internacionais. No escritório de Tóquio eu conversava com o consultor sobre visto de trabalho, com outro consultor sobre legislação das empresas internacionais (A2E1).

A classe 5, denominada de 'ação para colocação do produto no mercado internacional', compreende $17,6 \%$ do total do corpus analisado e é composta por palavras e radicais com intervalo qui-quadrado entre $X^{2}=5,53$ (aqui) e $X^{2}=24,8$ (próximo). As seguintes palavras se destacam: próximo $\left(X^{2}=24,8\right)$, Brasil $\left(X^{2}=\right.$ $18,04)$, grande $\left(X^{2}=12,21\right)$, visitar $\left(X^{2}=5,16\right)$, tocar $\left(X^{2}\right.$ $=5,16)$ e colocar $\left(X^{2}=4,66\right)$. Nesta classe encontramse os termos que simbolizam as ações para colocação do produto no mercado internacional, tal como segue:

A gente está muito mais próximo do mercado americano porque essa dificuldade que a gente tem, Brasil e Índia, os americanos tem também. E, de fato. Então, por exemplo, uma empresa americana contrata um indiano e eles alocam aqui no Brasil, eles podem cobrar por ponto de função, eu cobro ele por metro quadrado de piso que eu assento e não por hora de trabalho, então, eu consigo me tornar mais mensurável e palpável para os americanos o que também interessa para eles do ponto de vista de métrica, de produtividade. Com essas experiências fora entendendo como é que eles trabalham e nos processos de vendas também, de prospecção entendendo quais são as objeções e trabalhando para resolver essas objeções, São sete anos de construção para ter o primeiro contrato, então foi um longo caminho. (A3E1)

Eu fiz também pesquisa de mercado nos Estados Unidos, visitei muito lugares e é um 
mercado muito desenvolvido. O Japão já foi mais formal, no Japão você tem que agendar com três meses de antecedência, eles são formais, lá eu dizia: quero visitar mesmo os decasséguis que estão lá, são brasileiros que moram lá. (A2EE1).
Na Tabela 1 encontra-se uma síntese das classes referentes a conhecimentos adquiridos na experiência de internacionalização, com as denominações, percentuais em ordem de representatividade, considerando a quantidade de conteúdo representada pelas palavras.

Tabela 1 - Síntese da classificação do corpus relativo a conhecimentos gerados no processo de internacionalização

\begin{tabular}{c|l|c}
\hline Classe & Denominação & $\%$ \\
\hline 6 & Mercados e Destinos & $18,7 \%$ \\
\hline 5 & Ação para colocar o produto no mercado internacional & $17,6 \%$ \\
\hline 3 & Apoio e busca de conhecimentos externos & $16,5 \%$ \\
\hline 4 & Necessidade de qualificação para o processo de internacionalização e parcerias locais & $14,3 \%$ \\
\hline 1 & Visão do mercado local & $11 \%$ \\
\hline 2 & Complexidade do processo de internacionalização & $11 \%$ \\
\hline 7 & Adaptação a normas e mercados & $11 \%$ \\
\hline
\end{tabular}

Fonte: Dados da pesquisa

Em síntese, considerando as representações das classes de acordo com o percentual de palavras, mercado e destinos e ação para colocação do produto no mercado internacional apresentaram o maior percentual do corpus analisado (36,3\%). A classe 3, apoio e busca de conhecimentos externos, apresentou o terceiro maior percentual no corpus do texto, seguido da classe 4: necessidade de qualificação para o processo de internacionalização e parcerias locais, que representou $14,3 \%$. Essas quatro classes representam atividades de planejamento da internacionalização, requerendo aumento da capacidade de absorção e adaptação por parte das empresas.

As classes 1 (visão do mercado local), 2 (complexidade do processo de internacionalização) e 7 (adaptação a normas e mercados), que apresentaram o mesmo peso no total do corpus do texto (11\%), representam atividades mais associadas à implementação do processo de internacionalização.
Na sequência, foi realizada a análise fatorial por correspondência (AFC), em que as palavras, considerando-se sua incidência de frequência nas classes, foram representadas em um plano cartesiano. Na Figura 3, verifica-se que as classes 3, 5 e 4 encontram-se no mesmo quadrante (Q2). Tal representação já era esperada devido a relação entre essas classes citadas, uma vez que a classe 5 representa as ações para a colocação do produto no mercado internacional e, pelos relatos dos entrevistados, faz parte destas ações a busca por apoio e conhecimentos externos (classe 3), além da qualificação e de parcerias locais para viabilizar o processo de internacionalização (classe 4). Já as classes 7 (adaptação a normas e mercados) e 6 (mercado e destinos) encontram-se isoladas nos quadrantes 1 e 4, respectivamente, uma vez que os temas tratados nestas classes possuem tamanha relevância para o corpus do texto que necessitam serem tratadas em separado das demais classes. Essa representação corrobora com os dados do filograma apresentado na Figura 1. 


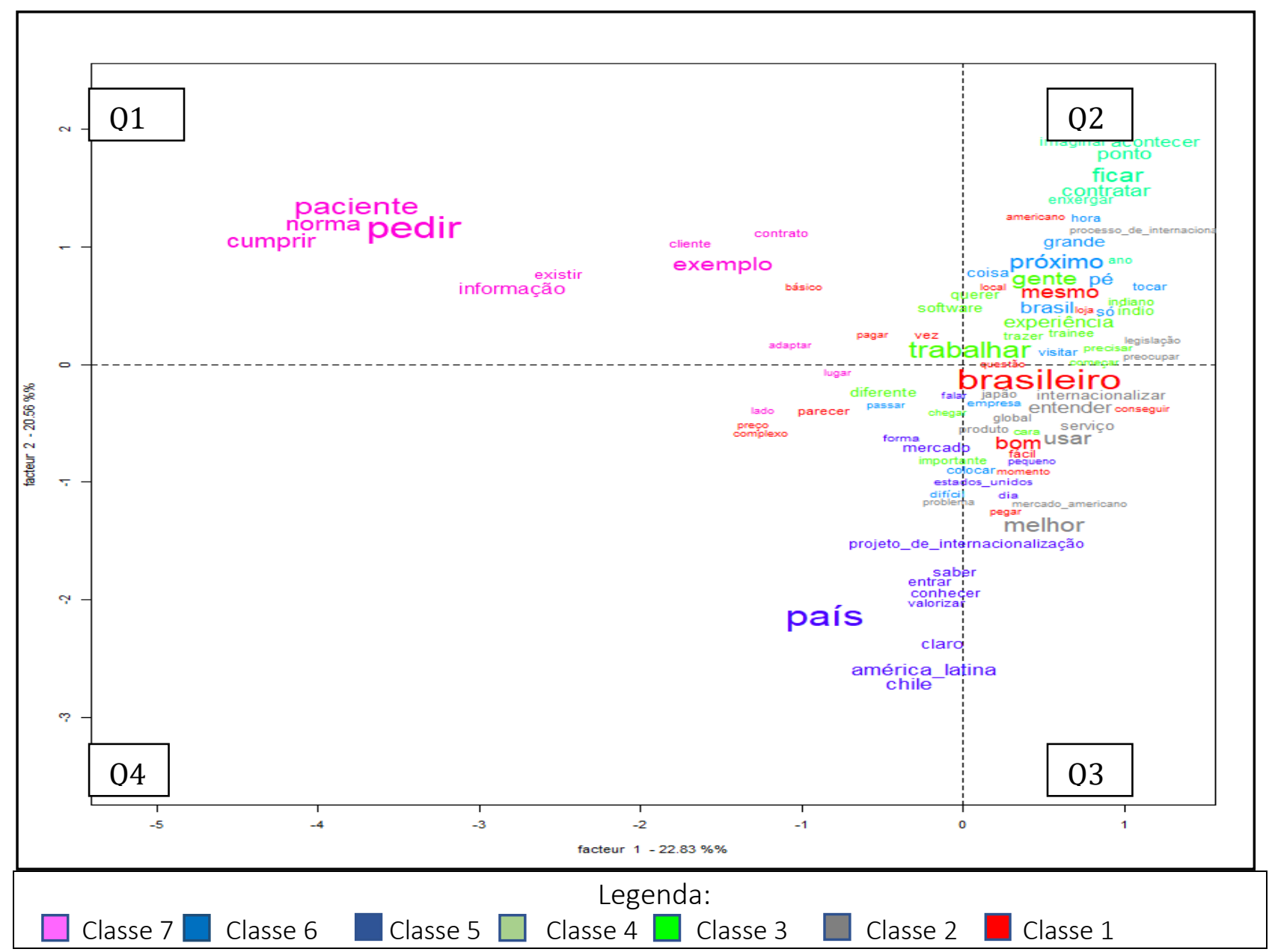

Figura 3. Análise Fatorial por Correspondência

Fonte: Elaboração própria com dados da pesquisa, 2018 e gerados pelo software IRaMuTeQ.

As classes 6 e 7, que se encontram isoladas na análise fatorial, representam respectivamente, mercados e destinos e adaptação a normas e mercados, e são representativas de ações de planejamento da internacionalização. As demais classes que ficaram agrupadas referem-se a: visão do mercado local (classe 1), complexidade do processo de internacionalização (classe 2), apoio e busca de conhecimentos externos (classe 3 ), necessidades de pessoas qualificadas para o processo de internacionalização (classe 4) e parcerias locais e ação para colocação do produto no mercado (classe 5), estão associadas à avaliação que os entrevistados fizeram sobre a efetiva entrada no mercado internacional e o aprendizado do processo. Com isso, observa-se que as experiências de internacionalização dessas empresas foram descritas em dois momentos: um de planejamento de ações e outro do efetivo processo de internacionalização.

De acordo com a nuvem de palavras, apresentada na Figura 4, as palavras mercado, país, empresa e Brasil aparecem com destaque, assim como outras palavras: produto, trabalhar, contrato, cliente, cultura, entender, software e projeto de internacionalização. Experiência, aprender e legislação podem ser visualizadas no quadrante superior esquerdo e, no quadrante superior direito: mercado, contratar solução, valorizar. No quadrante inferior esquerdo agruparam-se as palavras: conhecer, informação, problema, trainee. No quadrante inferior direito agruparam-se: entrar, dificuldade, complexo. 


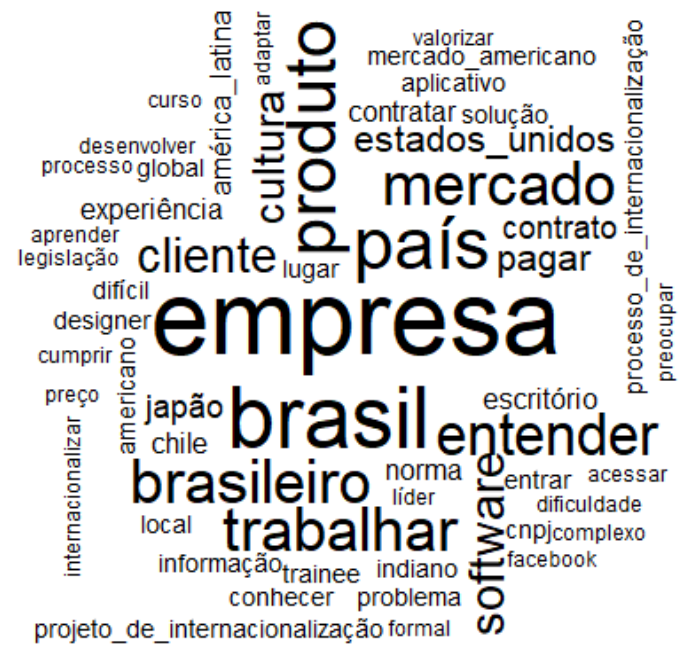

Figura 4. Nuvem de Palavras

Fonte: Elaboração com dados da pesquisa e gerados pelo aplicativo IRaMuTeQ.

\subsection{Análise dos resultados}

As empresas de software desta pesquisa utilizaram diferentes estratégias para entrada nos mercados internacionais: a) identificação de contato local; b) contratação de consultor; c) contato com outras empresas locais que se internacionalizaram; d) apoio de órgão público; e) viagem para o local de destino dos produtos. Tal como mostraram outros estudos (Cortezia \& Souza, 2007; Javernick-Will, 2009; Ramos \& Alperstedt, 2010), os empreendedores buscaram informações sobre o ambiente cultural, social e jurídico do país de destino, evidenciando um processo de planejamento da internacionalização. Nesse momento as empresas focaram mais na aprendizagem, como salientado também por Cortezia e Souza (2011), do que na busca de maximização de lucro (Linzemeyer et al., 2012). Ao buscar informações sobre o mercado local, eles visavam avaliar a oportunidade e o risco inerente ao processo de internacionalização, como descreve a abordagem do empreendedorismo internacional (McDougall \& Oviatt, 2003).

As empresas absorveram diferentes tipos de conhecimentos. Para Evangelista, Esposito, Lauro e Raffa (2010), empresas que se internacionalizam adquirem conhecimento de mercado, de tecnologia e conhecimento relacional. Nesta pesquisa, as empresas mencionaram conhecimentos de mercado, cultural e legal. A busca por conhecimento de mercado foi observada na classe 7 - adaptação a normas e mercados- e na classe 6 - mercado e destinos. A busca por conhecimento cultural foi identificada na classe 3 - apoio e busca de conhecimentos externos com parceiros, consultores, clientes e funcionários (neste último caso para a empresa que se internacionalizou para a Índia). Além 
destes, o conhecimento legal foi observado na classe 2 - complexidade do processo de internacionalização, em que os empreendedores mencionam a necessidade de adaptações a normas e legislação dos países de destino.

Além disso, como salientaram Mejri e Umemoto (2010) e Sullivan e Marvel (2011), o conhecimento acumulado na internacionalização pode gerar retornos no mercado local, na medida em que ele provoca a atração de novos clientes. Isso também foi observado nesta pesquisa, na classe 1 - visão do mercado local, evidenciando como a atuação internacional contribuiu para maior competitividade nacional.

Por fim, embora Limp et al. (2018) afirmem que a internacionalização não é dependente de trajetórias internacionais, nesta pesquisa a experiência de internacionalização resultou em um aprendizado do processo que pode estimular novas experiências em outros mercados, como mencionou o entrevistado A3:

Hoje pela minha experiência, pelo que vivi, não precisa muita coisa para internacionalizar, você precisa ter processos, é muito fácil abrir um CNPJ fora, muito fácil abrir um escritório virtual lá fora, por cem dólares você abre uma empresa lá e um escritório virtual, você contrata por quinze dólares um telefone nos Estados Unidos, aí alguém liga para você lá e você atende aqui (A3E2).

Em geral, os conhecimentos foram sendo obtidos de forma gradual, e, conforme o conteúdo das entrevistas, o conhecimento gerado na internacionalização se distinguiu em dois momentos: o de planejamento para entrada no mercado e o de adaptação e apoio na efetiva entrada no mercado local. Nesse sentido, a internacionalização seguiu um processo gradual, como menciona a abordagem de Upsala (Johanson \& Vahlne, 1977; 2009). No entanto, o processo não seguiu as etapas de exportação, abertura de subsidiária de vendas e implantação de unidade de produção, proposto por Johanson e Vahlne (2009). Como as empresas desta pesquisa atuam com serviços de software, os esforços de internacionalização foram concentrados na análise dos mercados e na ação para colocar o produto no mercado a partir de uma avaliação de condições legais, culturais e de mercado. Para isso, as empresas utilizaram parcerias com outras empresas, órgãos governamentais, redes e consultores, corroborando com a importância da construção de redes para a internacionalização (Hohenthal, Johanson, \& Johanson, 2014). Além disto, a busca de conhecimentos foi incentivada pelo comportamento dos empreendedores na avaliação do mercado, da oportunidade e dos riscos, uma dinâmica semelhante à explicada pela abordagem do empreendedorismo internacional (McDougall \& Oviatt, 2003).

De modo sucinto, os resultados desta pesquisa contribuíram para melhorar a validade e o escopo das abordagens anteriores do processo de internacionalização, salientando aspectos específicos do contexto de empresas de software (Fisher \& Aguinis, 2017). No que se refere à entrada em novos mercados, os resultados mostraram como as empresas utilizam diferentes estratégias, algumas não debatidas em estudos anteriores. Quanto à geração de conhecimento na internacionalização das empresas, de acordo com os resultados da pesquisa, as classes evidenciaram três categorias no processo de internacionalização: a) planejamento da internacionalização, abrangendo as seguintes classes: busca de contatos externos, visão do mercado local e complexidade do processo de internacionalização; b) adaptação para o processo de internacionalização, abrangendo a classe adaptação a normas e mercados; c) ação para colocação do produto no mercado local, abrangendo as classes: mercados e destinos, ação para colocar o produto no mercado internacional e busca de qualificação e de parcerias locais.

\section{Considerações Finais}

Esta pesquisa teve como objetivo identificar e analisar as formas de entrada e os conhecimentos obtidos por pequenas empresas de software em experiências de internacionalização. Inicialmente, destaca-se que as empresas utilizaram diferentes meios para se internacionalizar: parceiros locais, outras empresas que se internacionalizaram, consultores, órgãos públicos e viagens. Como conhecimentos gerados, foram identificadas seis classes de conhecimentos mencionados pelos empreendedores, sendo: a) mercados e destinos; b) ação para colocar o produto no mercado internacional; c) apoio e busca de conhecimentos externos; d) necessidade de qualificação para o processo de internacionalização e parcerias locais; e) visão do mercado local; f) complexidade do processo de internacionalização. Além disso, os dados 
mostraram a busca por conhecimentos de mercado, cultural e legal em dois momentos distintos: um associado ao planejamento da internacionalização e outro voltado à efetiva entrada no mercado internacional.

O estudo apresenta uma contribuição teórica, na medida em que avaliou o contexto de empresas de software localizadas em dois países, evidenciando que empresas de software se orientam por ações que abrangem elementos da escola comportamental e da escola empreendedora (Johanson \& Vahlne, 1977; 2009; McDougall \& Oviatt, 2007). Os resultados mostraram que o conhecimento nas experiências de internacionalização situou-se em três direções: planejamento, avaliação da internacionalização e ações para entrada no mercado internacional. Com isso, as empresas ampliaram o conhecimento sobre mercados internacionais, bem como reavaliaram suas práticas no mercado local. Como contribuição prática, os resultados apresentam elementos para outras empresas de software que pretendem se internacionalizar, bem como para a formulação de políticas voltadas a internacionalização dessas empresas.

Como limitação do estudo, menciona-se o fato do limitado número de países no âmbito das experiências de internacionalização. Estudos futuros com outros países podem trazer novas contribuições e explorar como o compartilhamento do conhecimento oriundo do processo de internacionalização junto a outras empresas, por exemplo, no âmbito de arranjos produtivos locais e de parques tecnológicos.

\section{Referências}

Amaral, L. M., Ribeiro, J. F., \& Sousa, M. (2007). Economia do Conhecimento: Noção, base de sustentação e tendências. Porto: SPI -Sociedade Portuguesa de Inovação.

An, X.; Deng, H., Chao, L., \& Bai, W. (2014). Knowledge management in supporting collaborative innovation community capacity building. Journal of Knowledge Management, 18(3), 574-590.

Anderson, S. (2000). Internationalization of the firm from an entrepreneurial perspective. International Studies of Management and Organization, 30(1): 63-92.
Agência Brasileira de Promoção de Exportações e Investimentos [ApexBrasil]. (2012). Prestação de contas ordinária anual: relatório de gestão do exercício de 2012. 18(3), 574-590.

Armario, J. M., Ruiz, D. M., \& Armario, E. M. (2008). Market Orientation and Internationalization in Small and Medium-Sized Enterprises. Journal of Small Business Management, 46(4), 485-511.

Bardin, L. (2010). Análise de conteúdo. 4. ed. Lisboa: Edições70.

Basañez, J. A. (2014). Metodología de Evaluación y Gestión del Conocimiento dinámico por procesos utilizando como soporte TIC el Entorno Colaborativo de Trabajo basado en el modelo de creación de Conocimiento de Nonaka-Takeuchi: Caso de estudio en el área de Gestión de proyectos de I+D+i en institución avanzada en Conocimiento. 190 f. Tese (Doutorado) - Curso de Gestión del Conocimiento, Universidad de Córdoba, Córdoba.

Burzynski, O. R., Graeml, A. R., Balbinot, Z. (2010). The internationalization of the software market: opportunities and challenges for Brazilian companies. JISTEM Revista de Gestão da Tecnologia e Sistemas de Informação, 7(3), 499-516.

Camargo, B. V., \& Justo, A. M. (2013). IraMuteq: Um software gratuito para análise de dados textuais. Temas em Psicologia, 513-518.

Cantú, L. E. Z. (2004). Los Determinantes de la Generación y la Transferencia del Conocimiento en Pequeñas y Medianas Empresas del Sector de las Tecnologias de la Información de Barcelona. 2004. 130f. Tese de Doutorado - Curso de Creación, Estratégia y Gestión de Empresas, Departament Déconomia de Lémpresa, UNiversitat Autònoma de Barcelona, Bellaterra (Cerdanyola del Vallès).

Cortezia, S. L. D., \& Souza, Y. S. (2007). Aprendizagem na Internacionalização de Micro e Pequenas Empresas da Indústria de Software. In Encontro Nacional da Associação Nacional de Programas de Pós-Graduação em Administração, Resumo dos trabalhos ENANPAD, Rio de Janeiro: ANPAD, 2007.

Cortezia, S. L. D., \& Souza, Y. S. (2011). Uma análise sobre a internacionalização de pequenas empresas 
brasileiras da indústria de software. $B B R$ - Brazilian Business Review, 8(4), 24-45.

Cunha, S. K. (2010). Processo de internacionalização de uma empresa multinacional brasileira de base tecnológica. Revista de Administração: FACES Journal, Belo Horizonte, 9(4), 67-84.

Davenport, T. H., \& Prusak, L. (2001). Conocimiento en acción: Cómo las organizaciones manejan lo que saben. Buenos Aires: Pearson Educación.

Dib, L. A., Rocha, A., \& Silva, J. F. (2010). The internationalization process of Brazilian software firms and the born global phenomenon: Examining firm, network, and entrepreneur variables. Journal of International Entrepreneurship, Rio de Janeiro, 8(3), 233-253.

Evangelista, P., Esposito, E., Lauro, V., \& Raffa, M. (2010). The Adoption of Knowledge Management Systems in Small Firms. Electronic Journal of Knowledge Management, 8(1), 33-42.

Fisher, G., Aguinis, H. (2017). Using Theory Elaboration to Make Theoretical Advancements. Organizational Research Methods, 20(3), 438-464.

França, A. A., L., Maccari, E.a., Da Costa, P. R. (2019). Capacidades dinâmicas e internacionalização da inovação: o caso Siemens Brasil. Revista Eletrônica de Negócios Internacionais, 14(1), 76-92.

Hohenthal, J., Johanson, J., \& Johanson, J. (2014). Network knowledge and business-relationship value in the foreign market. International Business Review, 23(1), 4-19.

Ibeh, K., Kasem, L. (2011). The network perspective and the internationalization of small and medium sized software firm from Syria. Industrial Marketing Management, 40, 358-367.

Javernick-Will, A. N. (2009). Organizational learning during internationalization: acquiring local institutional knowledge. Construction Management and Economics, 27(8), 783-797.

Johanson, J., \& Vahlne, J. E. (1977). The Internationalization Process of the Firm - A Model of Knowledge Development and Increasing Foreign Market Commitments. Journal of International Business Studies, 8(1), 23-32.
Johanson, J., \& Vahlne, J. E. (2009). The Uppsala internationalization process model revisited: from liability of foreignness to liability of outsidership. Journal of International Business Studies, 40(9), 1411 1431.

Lemes, I., \& Prates, R. C. (2014). A trajetória de Internacionalização e seu Reflexo na Aprendizagem Organizacional: um estudo de caso em uma indústria do segmento médio-odontológico. Desenvolvimento em Questão, 12(25), 153-188.

Limp, A., Rezende, S. F. L., \& Versiani, A. F. (2018). Customer relationships and interdependences in the internationalization process of firm. RAUSP Management Journal, 53, 109-121.

Linzemeyer, S. V. L., Souza, C. L., \& João, B. N. (2012). O processo de internacionalização de uma empresa do setor encaroçador. Revista Administração em Diálogo - RAD, São Paulo, 14(1), 56-78.

Mais, I., Carvalho, L. C., Amal, M., \& Hoffmann, M. G. (2010). Importância das redes nos processos de inovação e internacionalização de empresas de base tecnológica. Revista de Administração e Inovação, São Paulo, 7(1), 41-61.

Makambe, U. (2015). Perspectives on Knowledge Management - A Literature Review. Information and Knowledge Management, 5(1), 88-97.

Massago, Y., Leal, G. C. L., Balancieri, R., Galdamez, E. V. C. (2018). Towards classifying sociocultural aspects in Global Software Development. Journal of Information Systems and Technology ManagementJistem, 15, 1-19.

Massago, Y., Tanno, D. R., Balancieir, R., Leal, G. C. L., Galdamez, E. V. C., Huzita, E. (2019). Influência dos aspectos socioculturais em um modelo de maturidade para gestão do conhecimento. Revista Brasileira de Sistemas de Informação, 12(4), 64-97.

Mcdougal, P. P., \& Oviatt, B. M. (2003). Some fundamental issues in international entrepreneurship. Disponível em: <http://www.usasbe.org/knowledge/whitepapers/in dex.asp>. Acesso em: maio 2016. 
Mejri, K., Umemoto, K. (2010). Small- and medium-sized enterprise internationalization: Towards the knowledge-based model. Journal of International Entrepreneurship, 8(2), 156-167.

Nascimento, A. R. A., \& Menandro, P. R. M. (2006). Análise lexical e análise de conteúdo: Uma proposta de utilização conjugada. Estudos e Pesquisas em Psicologia, 6(2), 72-88.

Nonaka, I., \& Takeuchi, H. (1997). Criação de Conhecimento na Empresa: Como as empresas japonesas geram a dinâmica da inovação. 20 ed. Rio de Janeiro: Elsevier.

Ramos, W., \& Alperstedt, G. D. (2010). O processo de internacionalização de uma empresa de software para moda: da incubadora ao investimento direto no exterior. Internext: Revista Eletrônica de Negócios Internacionais da ESPM, São Paulo, 5(2), 66-90.

Ramos, M. G., Lima, V. M. R., \& Rosa, M. P. A. (2018). Contribuições do software IRAMUTEQ para a análise textual discursiva. Atas: Investigação Qualitativa em Educação, 2, 505-514.

Rezende, O., \& Campos, L. A. G. (2010). Internacionalização de empresas e o modelo dinâmico de aprendizagem: estudo de caso de uma empresa do setor de pedras ornamentais. Pretexto, Belo Horizonte, 11(2), 58-79.

Ribeiro, F. F., Oliveira Junior, M. M., \& Borini, F. M. (2012). Internacionalização acelerada de empresas de base tecnológica: o caso das Born Globals brasileiras. Revista de Administração Contemporânea, Curitiba, 16(6), 866-888.

Rivero, J. A. G. (2010). Administración del conocimiento y modelos de calidad como estrategias competitivas en las pequeñas y las medianas empresas de software. 2010. $130 \mathrm{f}$. Tese (Doutorado) - Curso de Ciencias Con Especialidad En Administración, Instituto Politécnico Nacional, Ciudad de México.

Salviati, M. E. (2017). Manual do aplicativo Iramuteq. Disponível em: $<$ http://iramuteq.org/documentation/fichiers/manu al-do-aplicativo-iramuteq-par-mariaelisabethsalviati>. Acesso em: 13 jan. 2019.
Silva, R. C. M., Chauvel, M. A., \& Bertrand, H. (2010). Internacionalização de Pequenas Empresas: Um Estudo de Caso com uma Empresa Brasileira de Tecnologia. Gestão \& Regionalidade, 26(76), 43-62.

Souza, A. E., Vasconcellos, E. P. G., \& Corrêa, H. L. (2012). O processo de internacionalização de empresas de software: o caso Audaces. Internext: Revista Eletrônica de Negócios Internacionais da ESPM, São Paulo, 7(20), 1-25.

Stal, E. (2010). Internacionalização de empresas brasileiras e o papel da inovação na construção de vantagens competitivas. Revista de Administração e Inovação, 7(3), 121-149.

Sullivan, D. M., \& Marvel, M. R. (2011). Knowledge Acquisition, Network Reliance, and Early-Stage Technology Venture Outcomes. Journal of Management Studies, 48(6), 1169-1193.

Tzortzaki, A. M., \& Mihiotis, A. A. (2014). Review of Knowledge Management Theory and Future Directions. Knowledge and Process Management, 21(1), 29-41.

Vasilchenko, E., Morrish, S. (2011). The role of entrepreneurial networks in the exploration and exploitation of internationalization opportunities by Information and Communication Technology Firms. Journal of International Marketing, 19(4), 88-105.

Xie, Y. H., \& Suh, T. (2014). Perceived resource deficiency and internationalization of small- and medium-sized firms. Journal of International Entrepreneurship, 12(3), 207-229.

Yin, R. K. (2015). Estudo de caso: Planejamento e Métodos. 5. ed. Porto Alegre: Bookman, 290 p.

Zahra, S. A., Ireland, R. D., \& Hitt, M. A. (2000). International Expansion by New Venture Firms International Diversity, Mode of Market Entry, Technological Learning, and Performance. Academy of Management Journal, 43, 925-950.

Zarei, B., Nasseri, H., \& Tajeddin, M. (2011). Best practice network business model for internationalization of small and medium enterprises. Journal of International Entrepreneurship, 9(4), 299315. 
Sobre os Autores:

Alessandra Herranz Gazquez - Centro Universitário de Maringá - UNICEUMAR, Paraná, (Brasil). E-mail: alessandra@attos.com.br Orcid id: https://orcid.org/0000-0001-7024-1705

Hilka Pelizza Vier Machado - Centro Universitário de Maringá - UNICEUMAR, Paraná, (Brasil). E-mail: hilkavier@yahoo.com Orcid id: https://orcid.org/0000-0002-2554-0025

Arthur Gualberto Bacelar da Cruz Urpia - Centro Universitário de Maringá - UNICEUMAR, Paraná, (Brasil). E-mail: arthur.urpia@unicesumar.edu.br Orcid id: https://orcid.org/0000-0002-5273-6373

\section{INTERNATIONALIZATION EXPERIENCES OF SMALL SOFTWARE COMPANIES AND KNOWLEDGE GAINED}

Alessandra Herranz Gazquez, Hilka Pelizza Vier Machado, Arthur Gualberto Bacelar da Cruz Urpia Centro Universitário de Maringá - UNICEUMAR, Maringá, PR (Brasil)

\section{ARTICLE DETAILS}

\section{Article history:}

Received: 24 May 2019

Accepted: 01 December 2019

Available online May: 01 th 2020

Double Blind Review System

Scientific Editor

Ilan Avrichir

\section{Key words}

Internationalization Process

Small business

Software

\section{ABSTRACT}

Purpose: The objective of this research was to identify and analyze the input forms and the knowledge obtained by small software companies in internationalization experiences.

Method: It is a qualitative study, conducted with five case studies of small entrepreneurs. Primary and secondary data were used. Primary data were obtained from nine open and semi-structured interviews, and secondary data from company websites. Data were categorized into input forms and knowledge obtained. Data from the latter category were complementarily analyzed using Iramuteq software. Findings: As generated knowledge, six classes of knowledge were identified: a) markets and destinations; b) action to place the product on the international market; c) support and search for external knowledge; d) need for qualification for the internationalization process and local partnerships; e) local market vision; f) complexity of the internationalization process.

Originality/value: The study of internationalization experiences and knowledge gained is an original approach as it highlights the ways in which small software companies gain input and experience in internationalization experiences.

Theoretical/Methodological Contributions: The results showed that learning in internationalization experiences favored the increase of international market knowledge and contributed to improve competitiveness in the local market. 


\title{
EXPERIENCIAS DE INTERNACIONALIZACIÓN DE PEQUEÑAS EMPRESAS DE SOFTWARE Y CONOCIMIENTOADQUIRIDO
}

\author{
Alessandra Herranz Gazquez, Hilka Pelizza Vier Machado, Arthur Gualberto Bacelar da Cruz Urpia \\ Centro Universitário de Maringá - UNICEUMAR, Maringá, PR (Brasil)
}

DETALLES DEL ARTÍCULO

\section{Historia del Artículo:}

Recibido: 24 de Mayo de 2019

Aceptado: 01 de Diciembre de 2019

Disponible en línea: 01 de Mayo 2020

Double Blind Review System

Editor Científico

Ilan Avrichir

\section{Palabras-clave:}

Proceso de internacionalización

Pequeñas empresas

Software

\section{RESUMEN}

Objetivo: El objetivo de esta investigación fue identificar y analizar las formas de entrada y conocimiento adquirido por pequeñas empresas de software en experiencias de internacionalización.

Método: Este es un estudio cualitativo, realizado con cinco estudios de caso de pequeños empresarios. Se utilizaron datos primarios y secundarios. Los datos primarios se obtuvieron de nueve entrevistas abiertas y semiestructuradas, y los datos secundarios de los sitios web de la compañía. Los datos se clasificaron en formularios de entrada y conocimiento obtenido. Los datos de la última categoría se analizaron de forma complementaria utilizando el software Iramuteq.

Resultados principales: a medida que se generó el conocimiento, se identificaron seis clases de conocimiento: a) mercados y destinos; b) acciones para colocar el producto en el mercado internacional; c) apoyo y búsqueda de conocimiento externo; d) necesidad de calificación para el proceso de internacionalización y asociaciones locales; e) visión del mercado local; f) complejidad del proceso de internacionalización.

Relevancia / Originalidad: el estudio de las experiencias de internacionalización y el conocimiento adquirido es un enfoque original, ya que destaca las formas en que las pequeñas empresas de software obtienen aportes y experiencia en experiencias de internacionalización.

Contribuciones teóricas / metodológicas: los resultados mostraron que el aprendizaje en experiencias de internacionalización favoreció el aumento del conocimiento del mercado internacional y contribuyó a mejorar la competitividad en el mercado local.

\section{Para citar este artigo:}

Gazquez, A., Machado, H., \& Urpia, A. (2020). Experiências de Internacionalização de Pequenas Empresas de Software e Conhecimentos Obtidos. Internext, 15(2), 18-36. doi: http://dx.doi.org/10.18568/internext.v15i2.573 